\title{
27. TOTAL FIELD MAGNETIC ANOMALIES AND TOPOGRAPHY ALONG A TRAVERSE BETWEEN JAPAN AND THE FIJI ISLANDS
}

\author{
E. John W. Jones, Department of Geology, University College, London \\ and \\ Bruce C. Heezen, Lamont-Doherty Geological Observatory, Columbia University, Palisades, New York
}

A proton magnetometer was operated during the passages between the DSDP Leg 20 drilling sites. The track of D.V. Glomar Challenger (Figure 1) ran from the outer ridge southeast of Japan past Marcus Island, Guam, and Kusaie and terminated in Suva, Fiji. Residual magnetic anomalies (in gammas), derived from the shipboard readings using the IGRF coefficients of Cain et al. (1968), are presented together with the bathymetric profile at the end of this chapter. Depths are indicated in tau, the conventional echo sounding unit ( $1 \tau=1 / 400 \mathrm{sec}$ total travel time). Along the top of the profile the time of day is marked, and along the bottom important positions are indicated. A detailed list of navigation coordinates is given in the chapter describing the seismic reflection profiles (Chapter 28).

The profiles between the northern drilling sites (194 to 198) lie to the south of a group of well-defined eastnortheast magnetic lineations which were mapped some years ago by Uyeda and others (Uyeda et al., 1967; Uyeda and Vacquier, 1968). To the east and northeast of the track between Sites 198 and 202 is situated another group of linear magnetic anomalies trending northeast (the Hawaiian lineations, Figure 2). South of Site 202 the track passes over a complex area including the Solomon Plateau and the Fiji Plateau which lie to the west and southwest of some east-northeast lineations south of the Magellan Plateau. The latter (the Phoenix group of anomalies) have recently been discussed by Larson and Chase (1972) who believe that the three sets form a single series of Mesozoic lineations.

In the area of the drilling sites the trends of the magnetic anomalies, if they are indeed linear, have not yet been elucidated. On the maps of Uyeda and others (Uyeda et al., 1967; Uyeda and Vacquier, 1968) the Japanese lineations reach no further south than $35^{\circ} \mathrm{N}$, and on the recent map of Larson and Chase (1972) the Hawaiian group extends no further west than $160^{\circ} \mathrm{E}$. If linear anomalies do exist between Sites 194 and 199, then they could belong to either the Japanese or the Hawaiian set, or both groups may be present in a magnetic bight similar to that described by Elvers et al. (1967) in the northeast Pacific. Because basement was not dated on Leg 20 , the age gradients remained undetermined.

It can be seen on the profile that anomalies of fairly large amplitude occur between Site 195 and a point just north of Site 198. Because much of this track runs approximately southeast, this suggests that if lineations are present they must trend in a direction closer to northeast than northwest. It appears, therefore, that the pattern in the area may be part of the Japanese set rather than the Hawaiian. Support for this conclusion comes from a consideration of the anomalies seen around Site 196 where a series of course changes was necessary before the final drilling location was established. On the approach to the site made along courses of $100^{\circ}-115^{\circ}$ on September 29 , three anomalies labeled A, B, and C are seen (Figure 3). On the track from Site 197 to Site $198\left(130^{\circ}\right.$; October 8$)$ these three anomalies can again be identified and indicate a lineation trend of $045^{\circ}$. It is interesting to note that there is topographic grain in this direction in the region of Sites 196 and 197 (Figure 3). This grain is interpreted as being imparted at the accretion center that generated the crust in this area.

At Site 198 the trend of the magnetic anomalies cannot be identified from the Challenger magnetic data. However, just north of this site a prominent northeasterly topographic grain is present (Figure 4) which suggests that magnetic lineations trend in this direction also. A low ridge running northwest is seen about 15 miles to the southeast of Site 198 (Figure 5), but south of there no trend is discernible. In the latter area the amplitude of the magnetic anomalies is small (less than 80-100 gammas). By combining the magnetic and topographic data, it is suggested that the Japanese lineations reach $25^{\circ} 30^{\prime} \mathrm{N}$ which is some 1000 $\mathrm{km}$ further south than they had been mapped previously by Uyeda and others (Uyeda et al., 1967; Uyeda and Vacquier, 1968). By accepting the conclusion of Larson and Chase (1972) that the Japanese lineations become younger as the trench is approached, it is implied that the crust is appreciably older at Site 198 than at Site 194. Presumably the crust at Site 199 is older still, although this cannot be supported by the magnetic data since the anomalies are of low amplitude in the area. Extrapolating either from the Japanese or the Hawaiian set indicates that the crust is oldest in the area of Site 199 which is at least consistent with the thick sedimentary succession there.

Since the Japanese lineations probably reach as far south as Site 198, crustal ages can be tentatively assigned using the time scale developed by Larson and Pitman (1972). By assuming that the spreading rates were not greatly different on the northern and eastern arms of the bight at the time anomalies M-10 and M-22 were generated, then anomaly M-22 would pass close to Site 194. The crust at Site 194 would then be Lower Kimmeridgian in age (148 m.y. approximately). According to these authors the area south of Site 194 should be magnetically quiet since they hold that the period encompassing the Callovian, Oxfordian, and Lower Kimmeridgian (162-148 m.y. B.P.) was one when no reversals occurred. However, evidence has been found to suggest that a lineation pattern is present belonging to the Japanese set with anomaly amplitudes usually exceeding 100 gammas. This suggests that the Callovian-Lower Kim- 


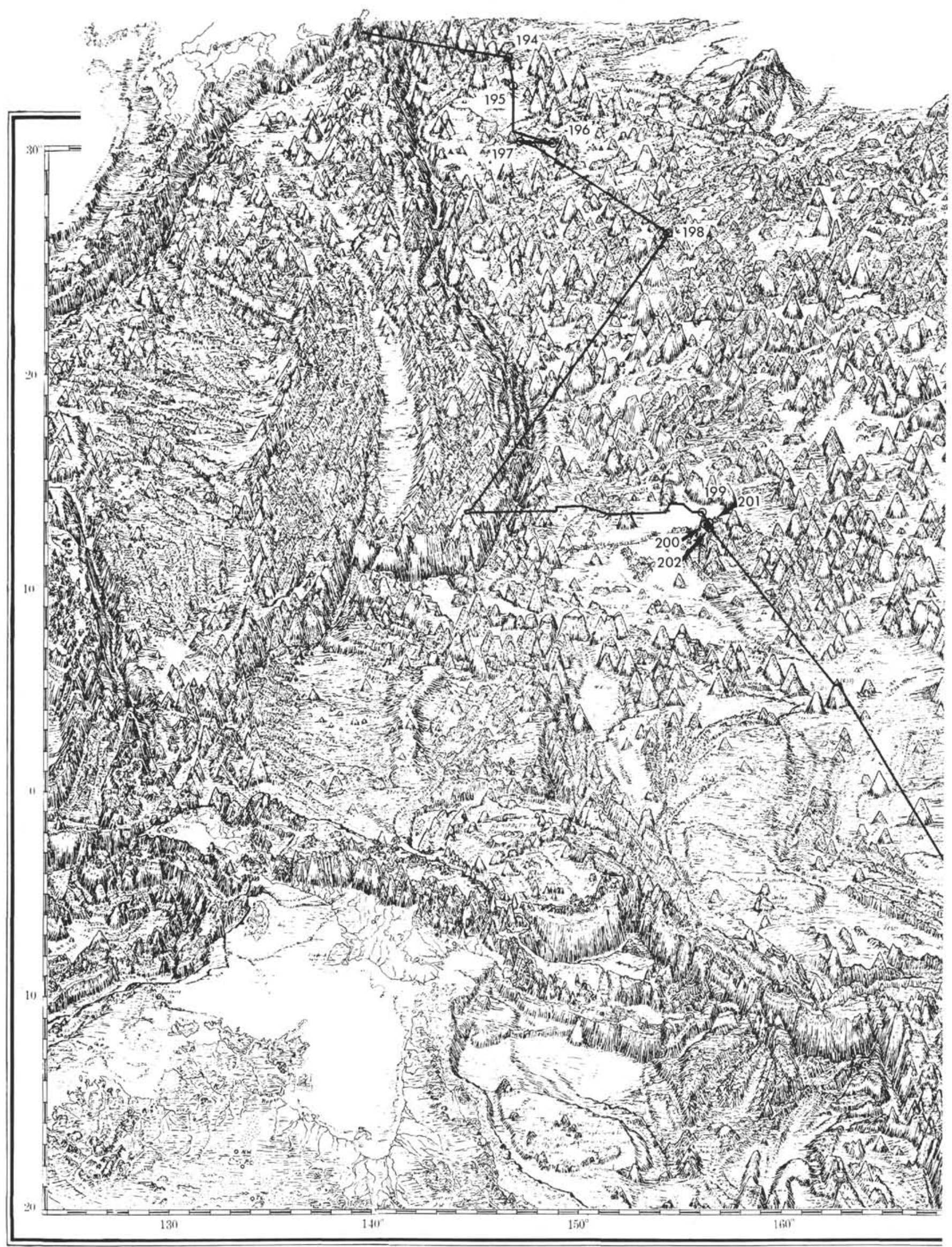

Figure 1. Track of D.V. Glomar Challenger between Yokohama, Japan and Suva, Fiji. 


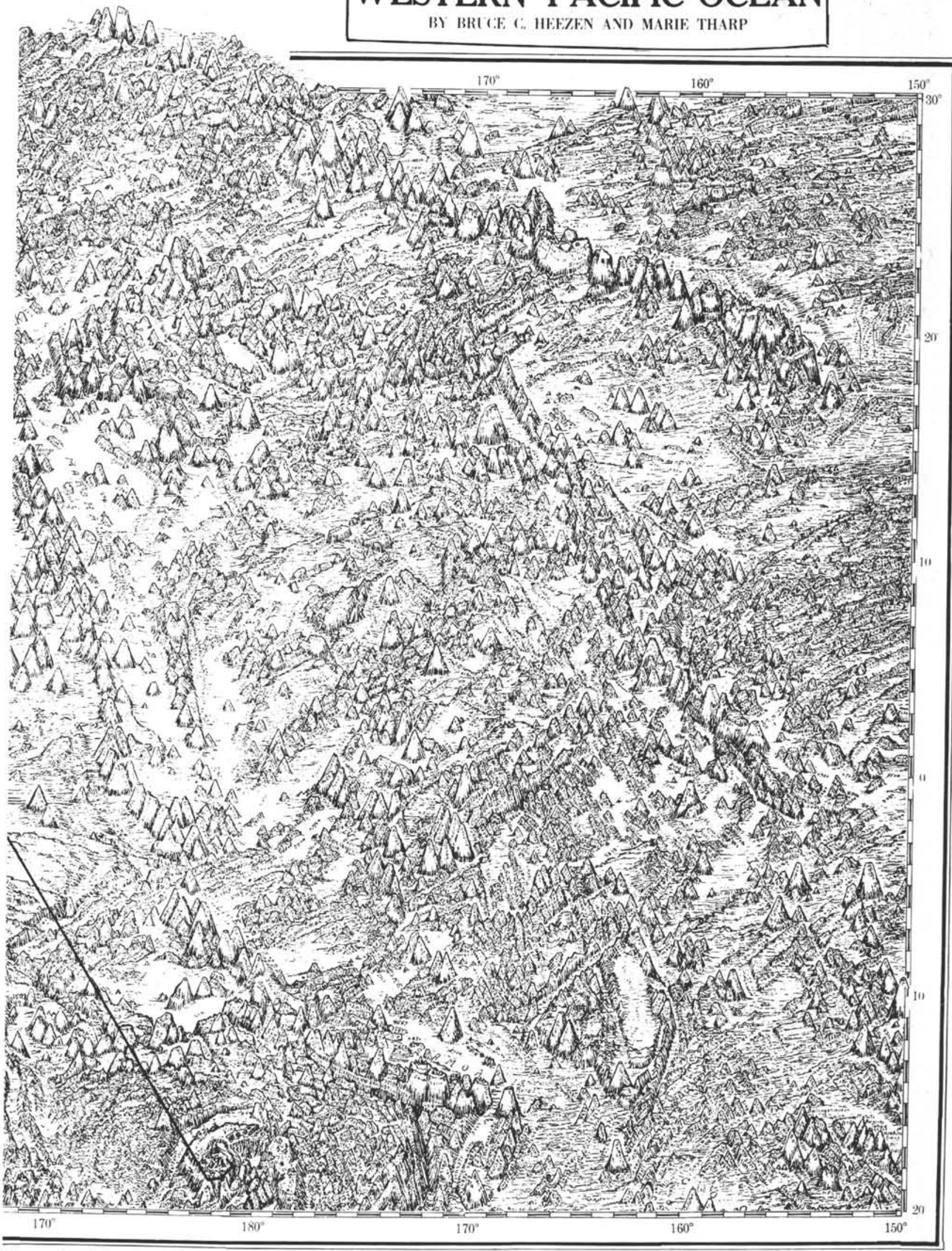

Figure 1. (Continued). 


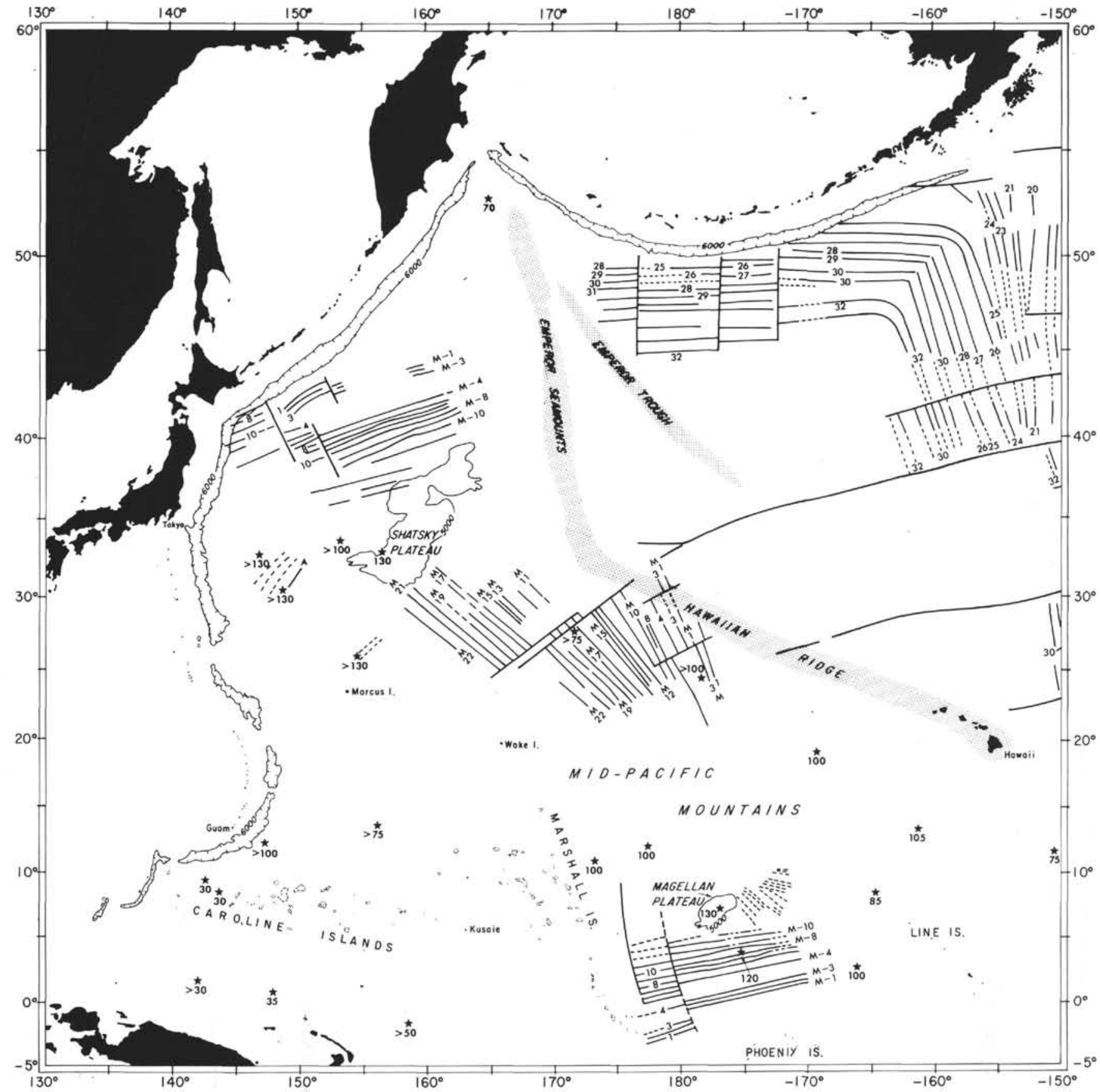

Figure 2. Magnetic anomaly trends in the North Pacific (after Larson and Chase, 1971). Trends SE of Japan are suggested by DSDP Leg 20 data. Stars give location of DSDP sites, accompanying figures represent maximum age of sediment drilled in m.y.

meridgian period did, in fact, have magnetic reversals. Assuming that no large changes in spreading rate occurred, an extrapolation between Sites 194 and 198 would suggest the crust beneath 198 is Middle Jurassic in age and is approximately 165 m.y. old. The magnetically quiet zone south of Site 198 is older still than this and it may have been formed in a period when there were no magnetic reversals or may be crust that was generated on the equator.

There are several places along the track over the "magnetically quiet area" (Larson and Chase, 1972) be- tween Sites 198 and 199 where high amplitude anomalies are present. Just east of the seaward wall of the Mariana Trench occur several seamounts with which pronounced negative anomalies are associated. Large anomalies also occur at the foot of the landward wall of the trench on the approach to Guam which is unexpected since the lithosphere supposedly dips steeply in this region and the oceanic basement should have lost its remanent magnetization. The magnetic anomalies at the foot of the landward wall are apparently not of regional extent as they are not 


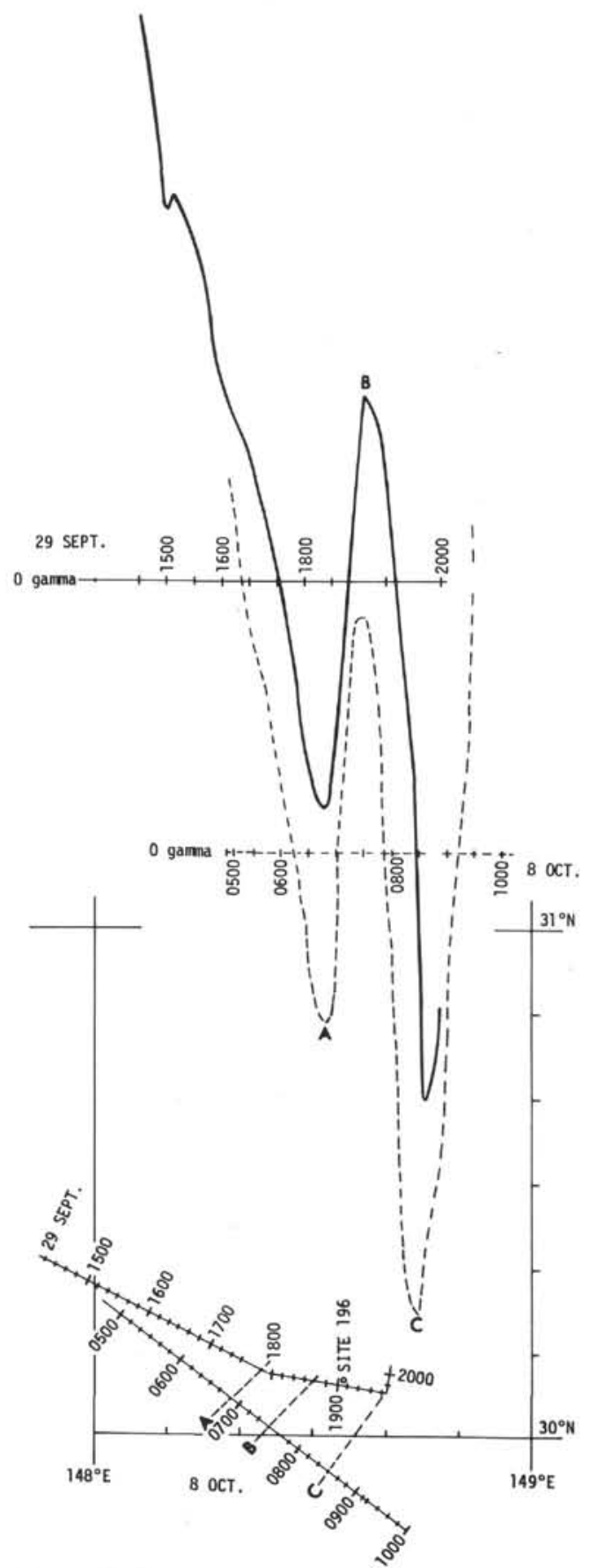

Figure 3. Magnetic anomalies near Site 196.

found on the track between Guam and Site 199. The anomalies may be related to quite local igneous activity.

In the area near Ita Maitai Guyot the relatively quiet field is disturbed by several large anomalies, the largest group (roughly 600 gammas amplitude) being associated with the Guyot itself.

On the track to the southeast of Ita Maitai Guyot the anomalies are relatively large $>100$ gammas) compared with those seen on the track towards Site 199. Although this whole region has been classified as magnetically quiet by Larson and Pitman (1972) it is believed that a pattern of lineations running in a direction closer to northeast than

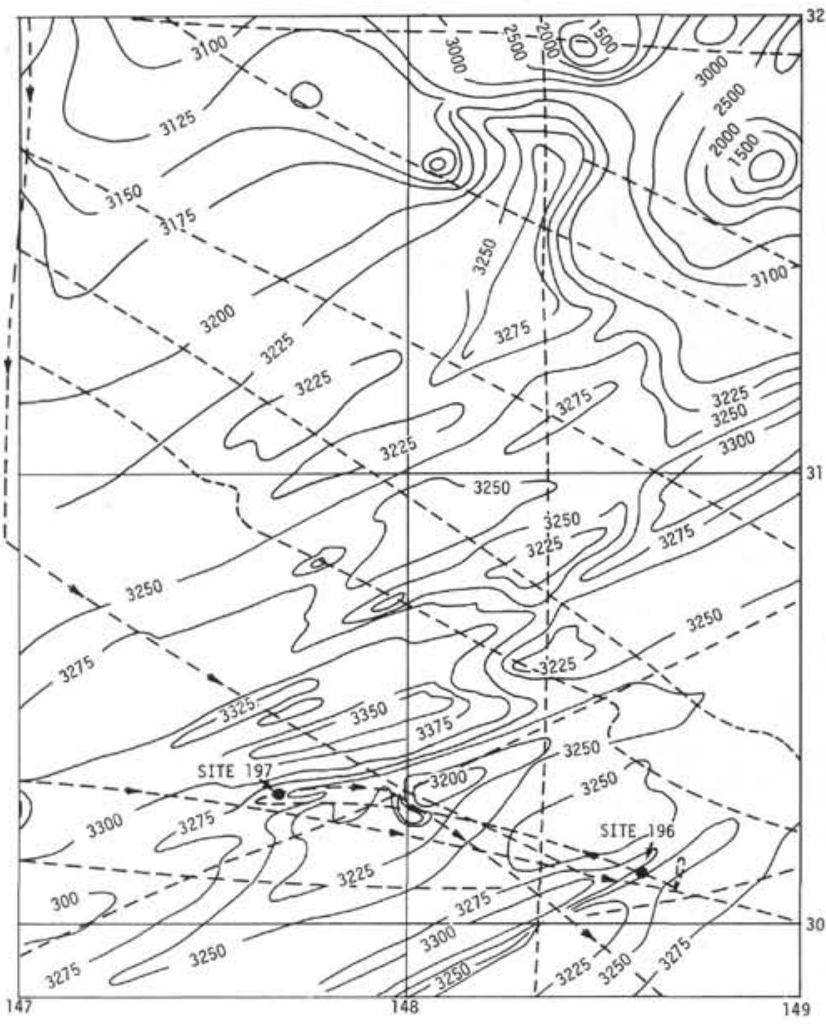

Figure 4. Bathymetry near Sites 196 and 197. Contours are expressed in tau $(1 \tau=1 / 400 \mathrm{sec})$.

northwest may be present and may eventually help to clarify the age of the crust in this region. The presence of such a pattern raises the possibility that there may be a further magnetic bight to the southwest of the Hawaiian set. If this is correct, then the oldest part of the Pacific crust may be located under the Caroline Abyssal Plain where it is relatively quiet magnetically. This is a location where it would be feasible to drill, despite the high reflectivity of the "opaque" layer, as drilling at Site 199 has shown it to be composed of unlithified turbidites.

High amplitude (>1000 gammas), short wavelength anomalies over the Fiji Plateau are in striking contrast to the anomalies seen further to the north. This is an area of sharp relief and thin sediment cover consistent with a young crustal age deduced by Chase (1971).

\section{REFERENCES}

Cain, J. C., Hendricks, S., Daniels, W. E., and Jensen, J. C., 1968. Computation of the main geomagnetic field from spherical harmonic expansions: Data User's Note NSSDC 68-11, Greenbelt, Md.

Chase, C. A., 1971. Tectonic history of the Fiji Plateau: Geol. Soc. Am. Bull., v. 82, p. 3087.

Elvers, D. J., Mathewson, C. C., Kohler, R. E., and Moses, R. L., 1967. Systematic ocean surveys by U.S.C. and G.S.S. Pioneer 1961-1963: Coast Geodetic Surv. Operational Data Rept. C and GSDR-1, 19.

Larson, R. L. and Chase, C. A., 1972. Late Mesozoic evolution of the Western Pacific Ocean: Geol. Soc. Am. Bull., v. 83, p. 3627.

Larson, R. L. and Pitman, W. C., 1972. World-wide correlation of Mesozoic magnetic anomalies and its implication: Geol. Soc. Am. Bull., v. 83, p. 3645. 


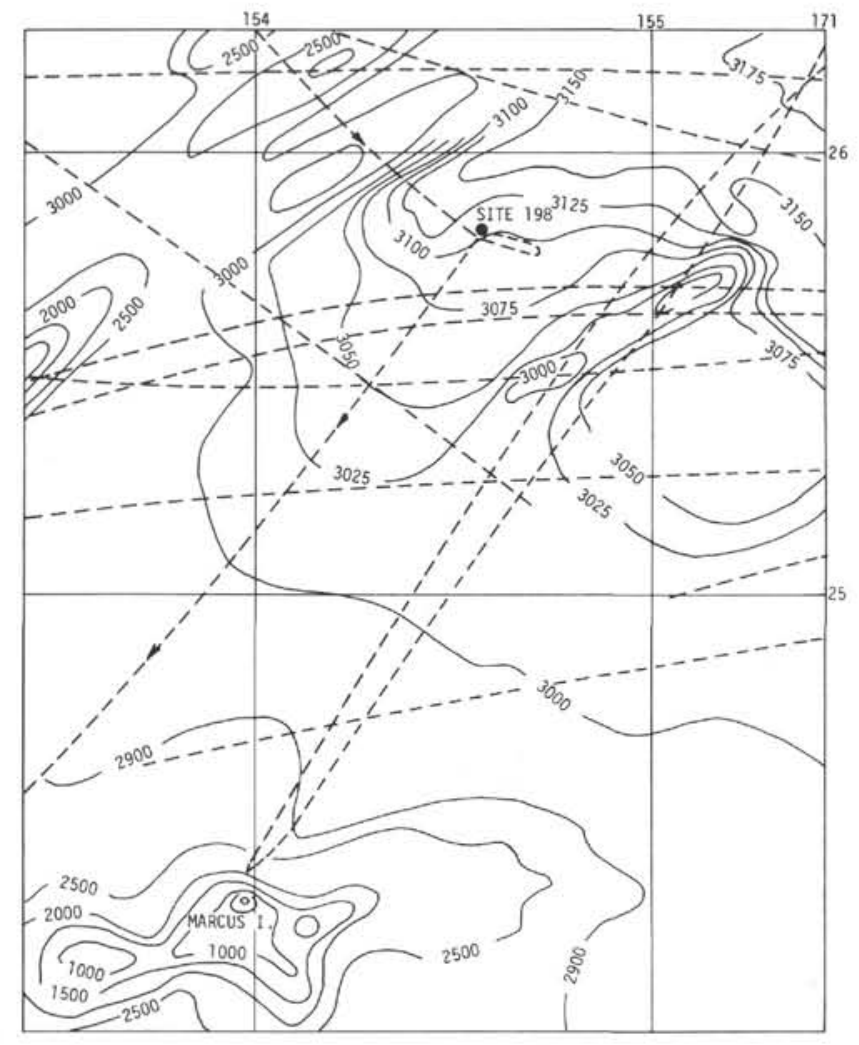

Figure 5. Bathymetry near Site 198. Contours are expressed in tau $(1 \tau=1 / 400 \mathrm{sec})$.
Uyeda, S. and Vacquier, V., 1968. Geothermal and geomagnetic data in and around the island of Japan. In Knopoff, L. et al. (Eds.), The crust and upper mantle of the Pacific area: Am. Geophys. Union Mono. No. 12, p. 349.

Uyeda, S., Vacquíer, V., Uasui, M., Sclater, J., Saito, T., Lowson, J., Watanabe, T., Dixon, F., Silver, E., Fukao, Y., Sudo, K., Nishikawa, M., and Tanaka, T., 1967. Results of geomagnetic survey during the cruise of $\mathrm{R} / \mathrm{V}$ ARGO in western Pacific 1966 and the compilation of magnetic charts of the same area: Tokyo Univ. Earthquake Res. Inst. Bull., v. 45, p. 799. 


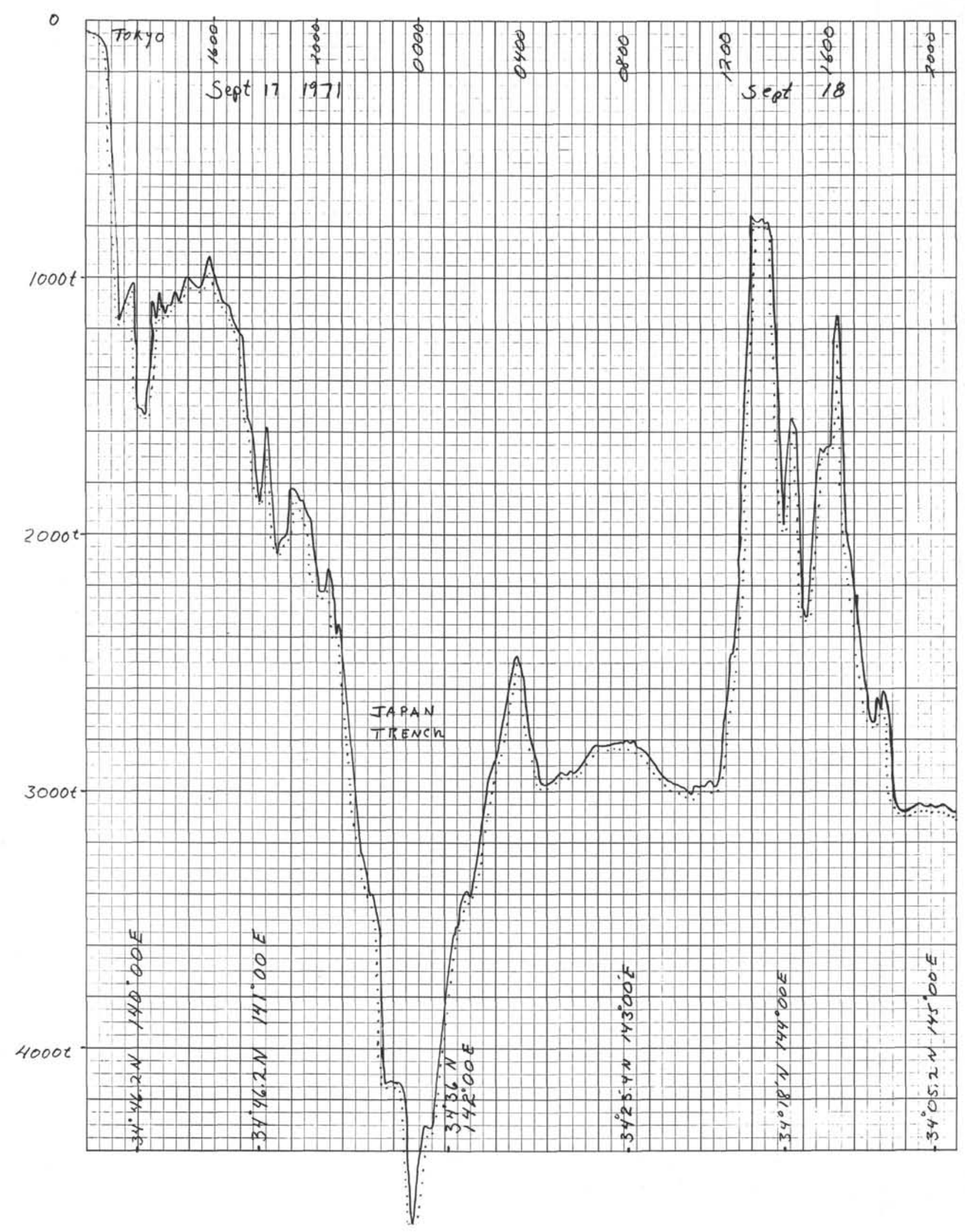




\section{E. J. W. JONES, B. C. HEEZEN}

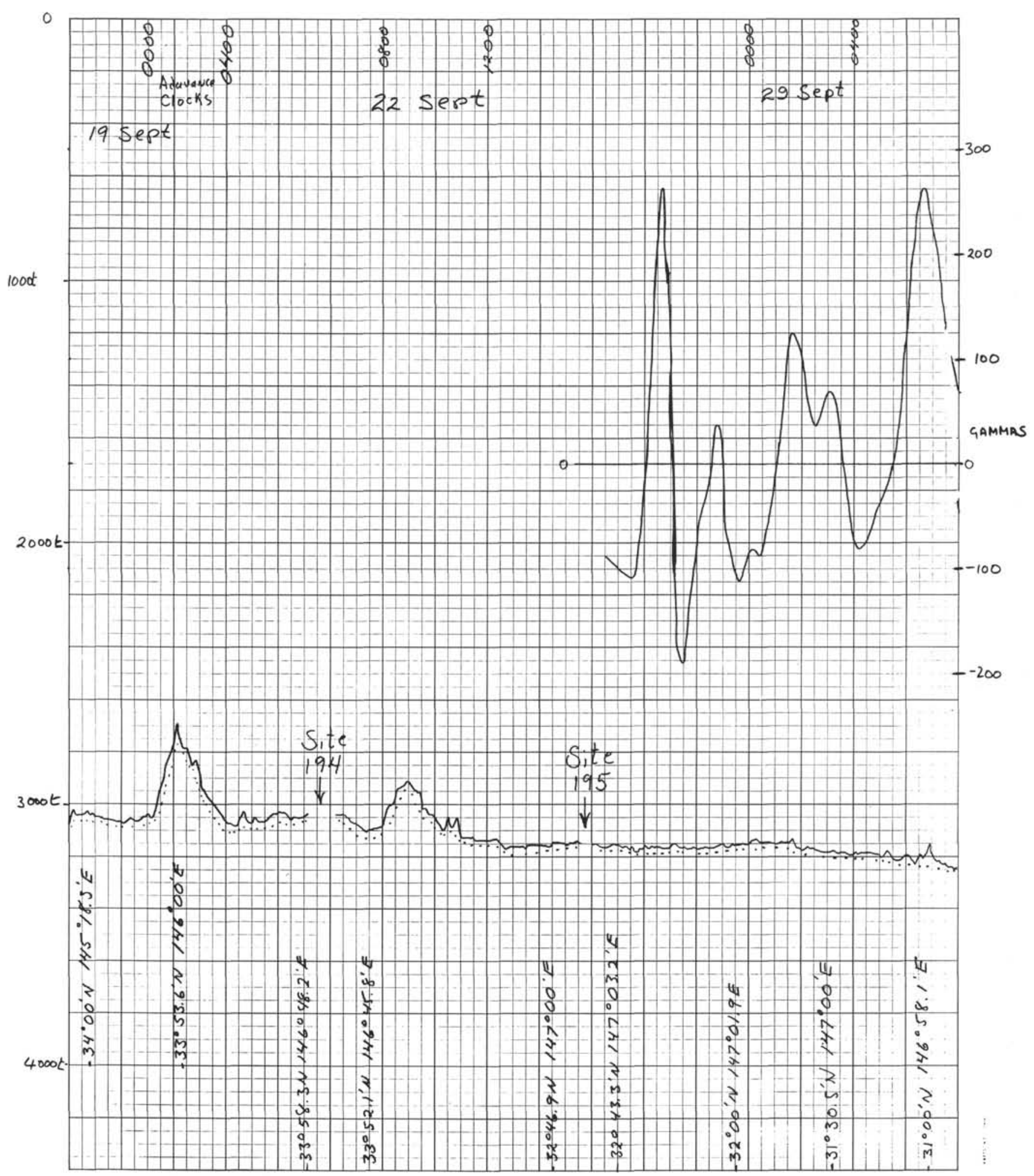




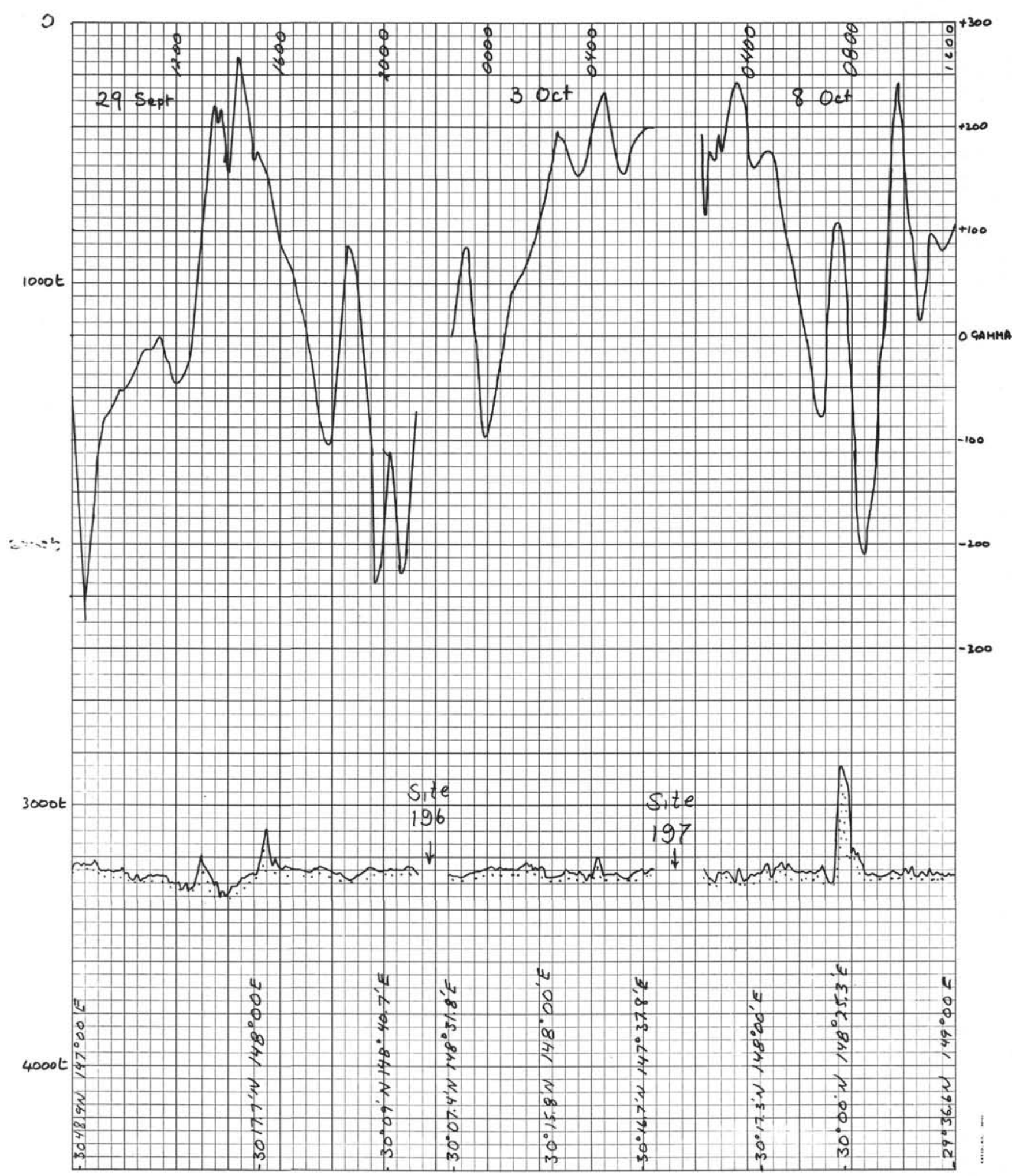




\section{E. J. W. JONES, B. C. HEEZEN}

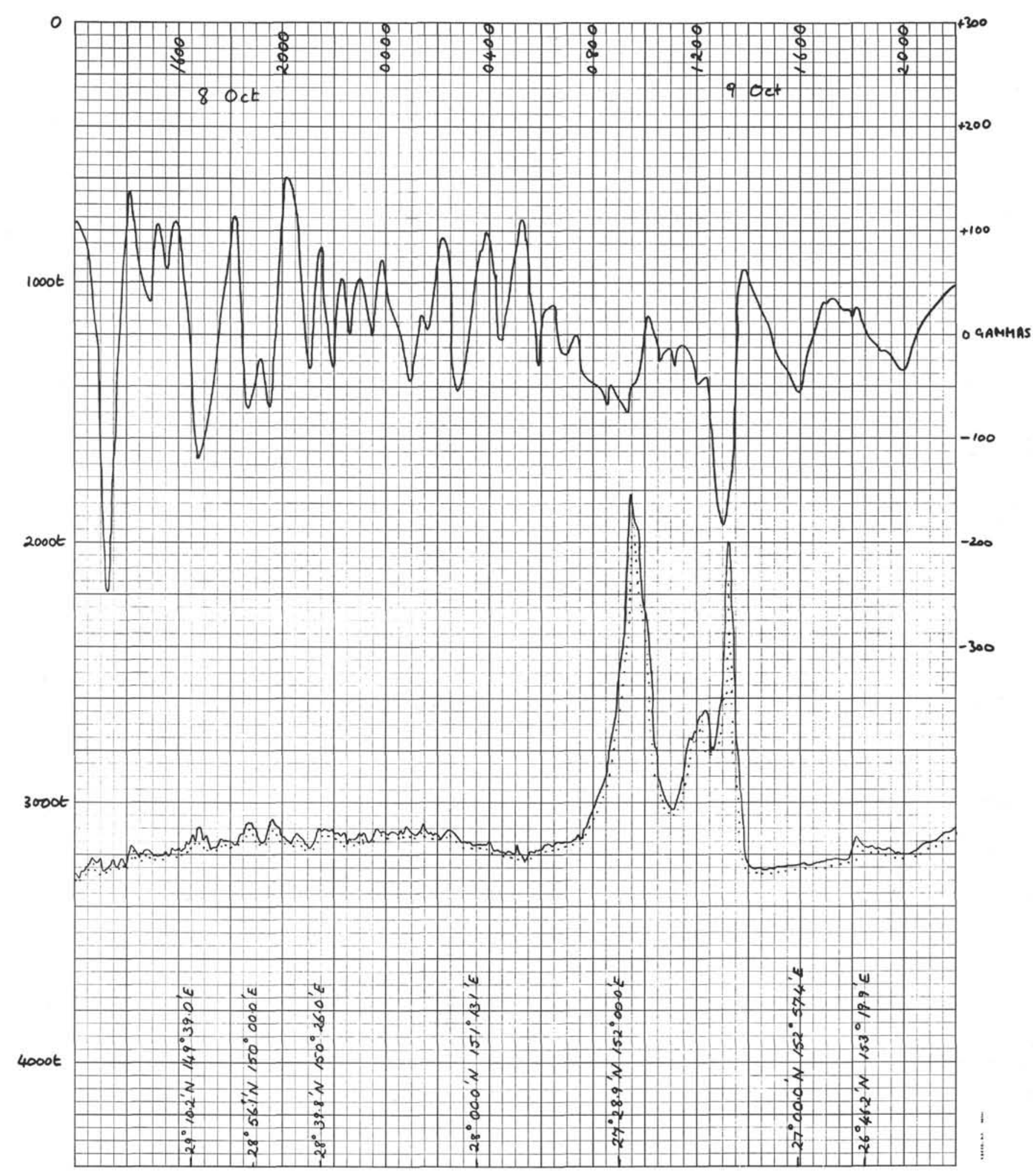




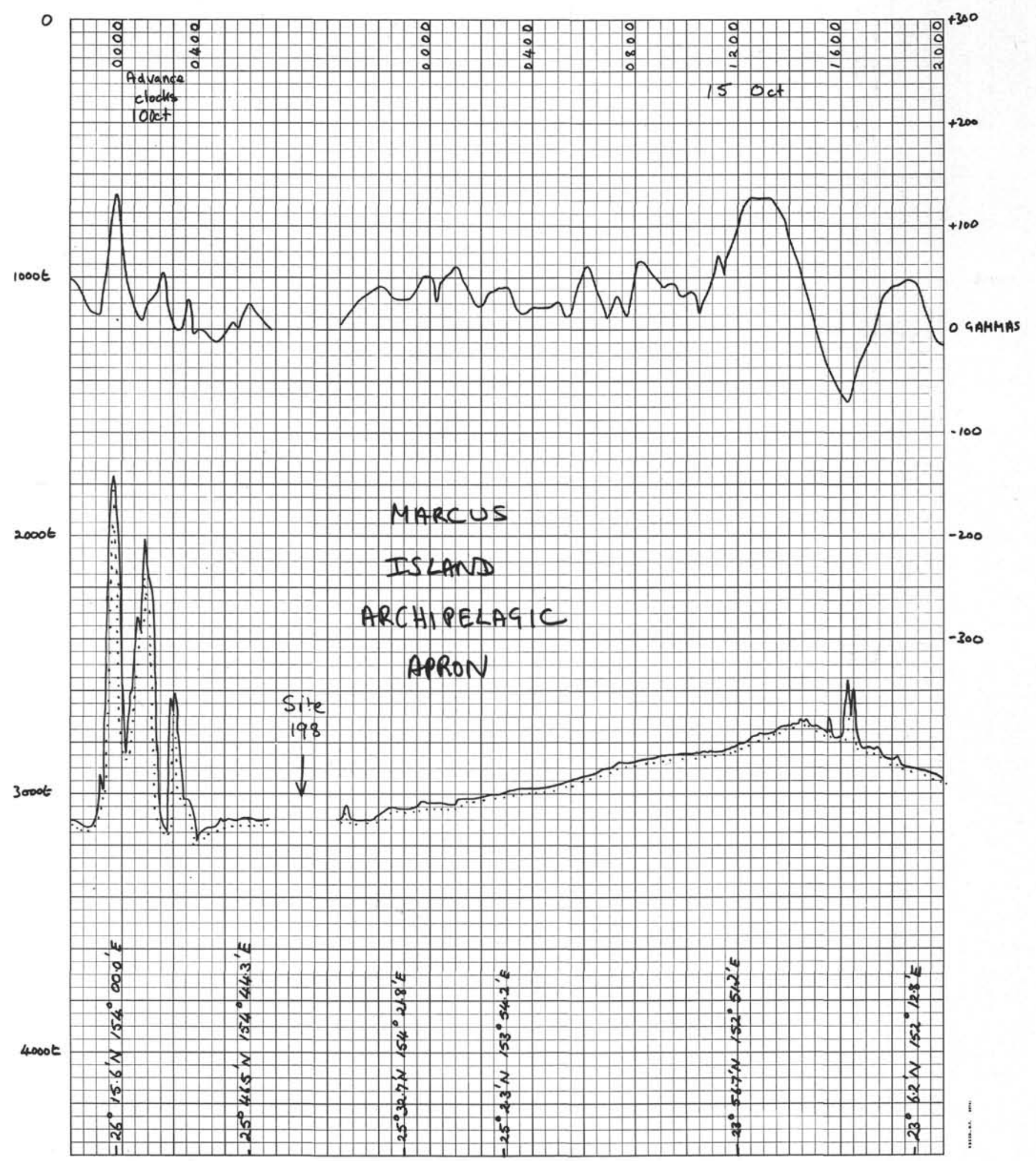




\section{E. J. W. JONES, B. C. HEEZEN}

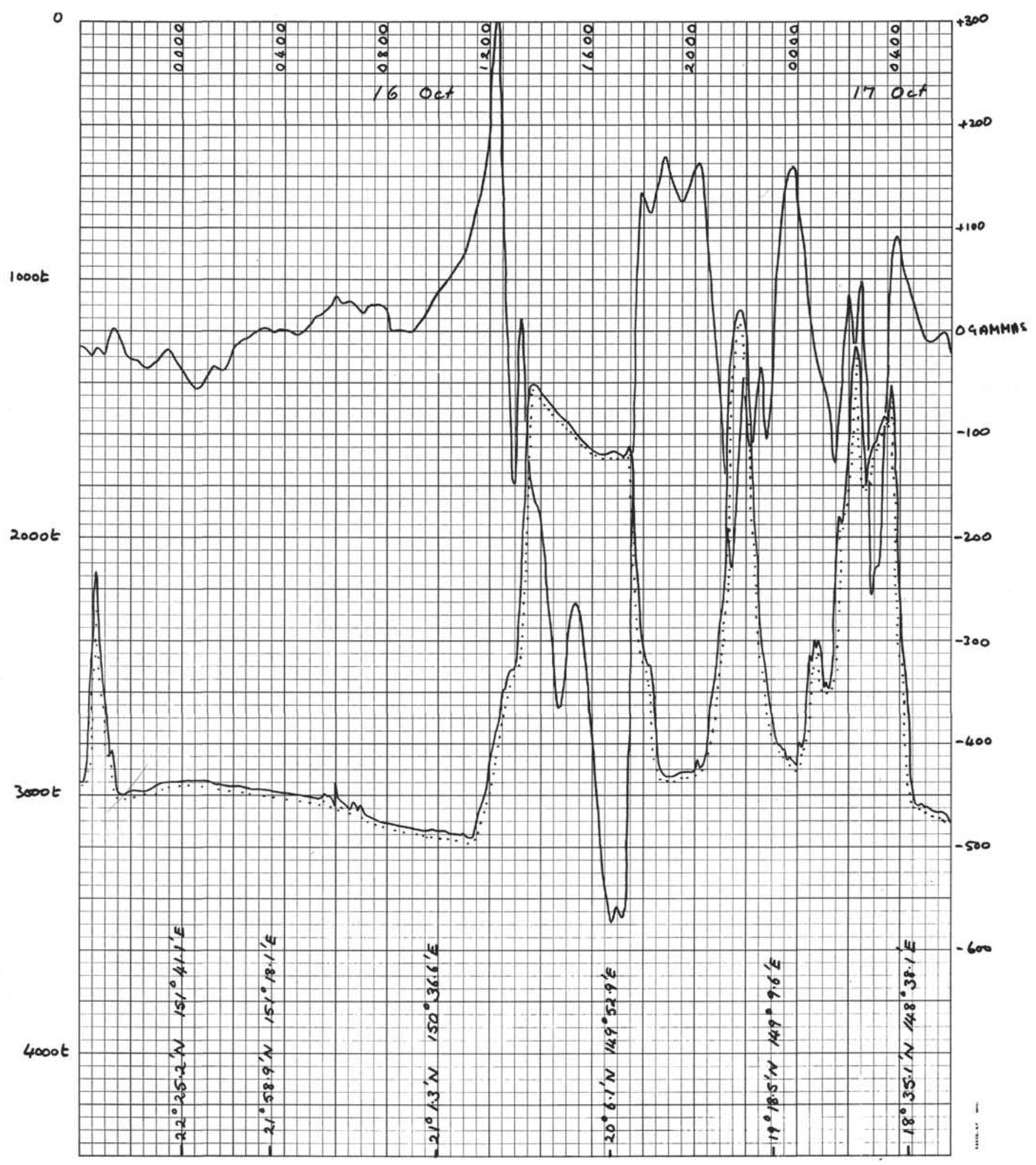




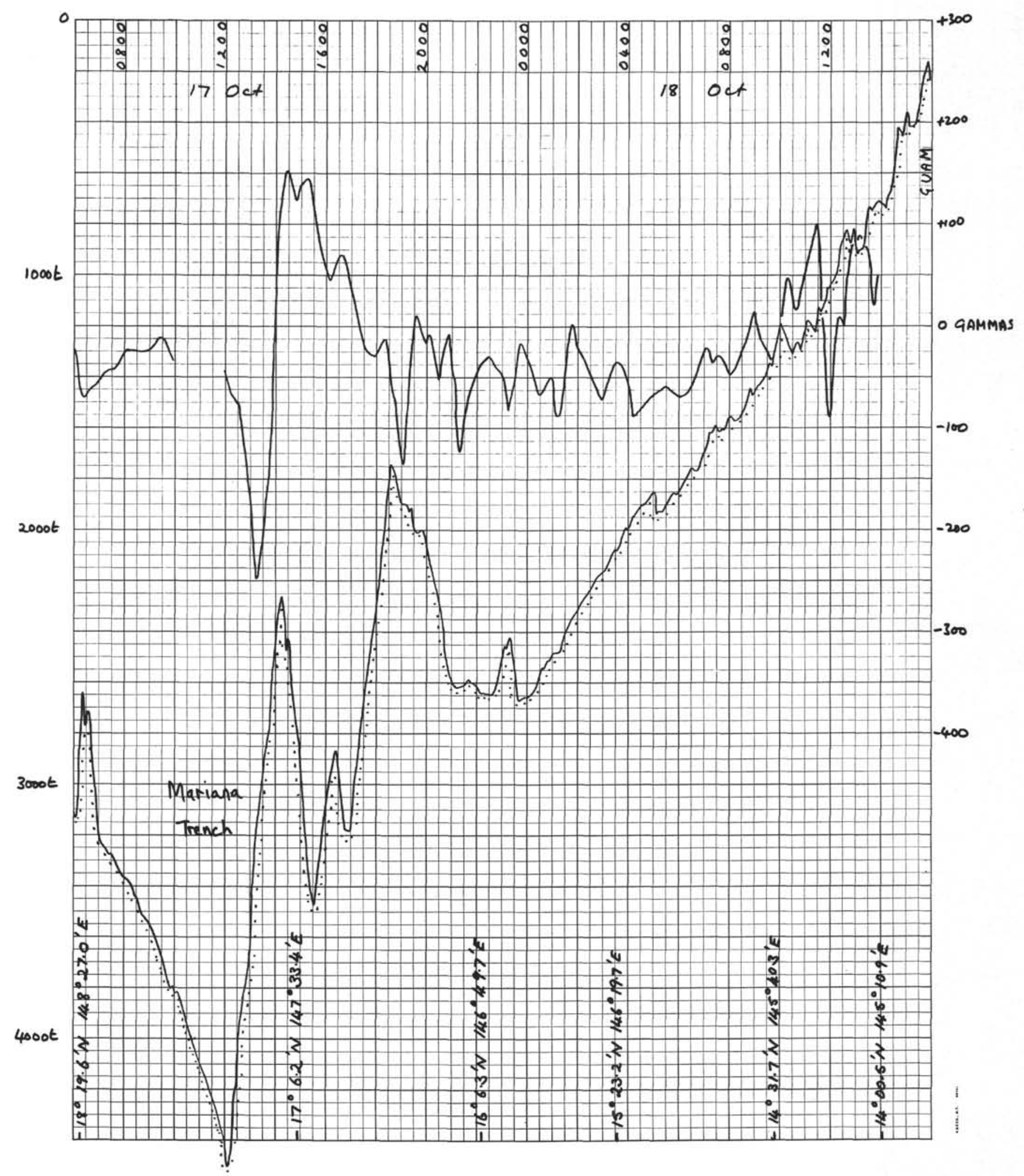


E. J. W. JONES, B. C. HEEZEN

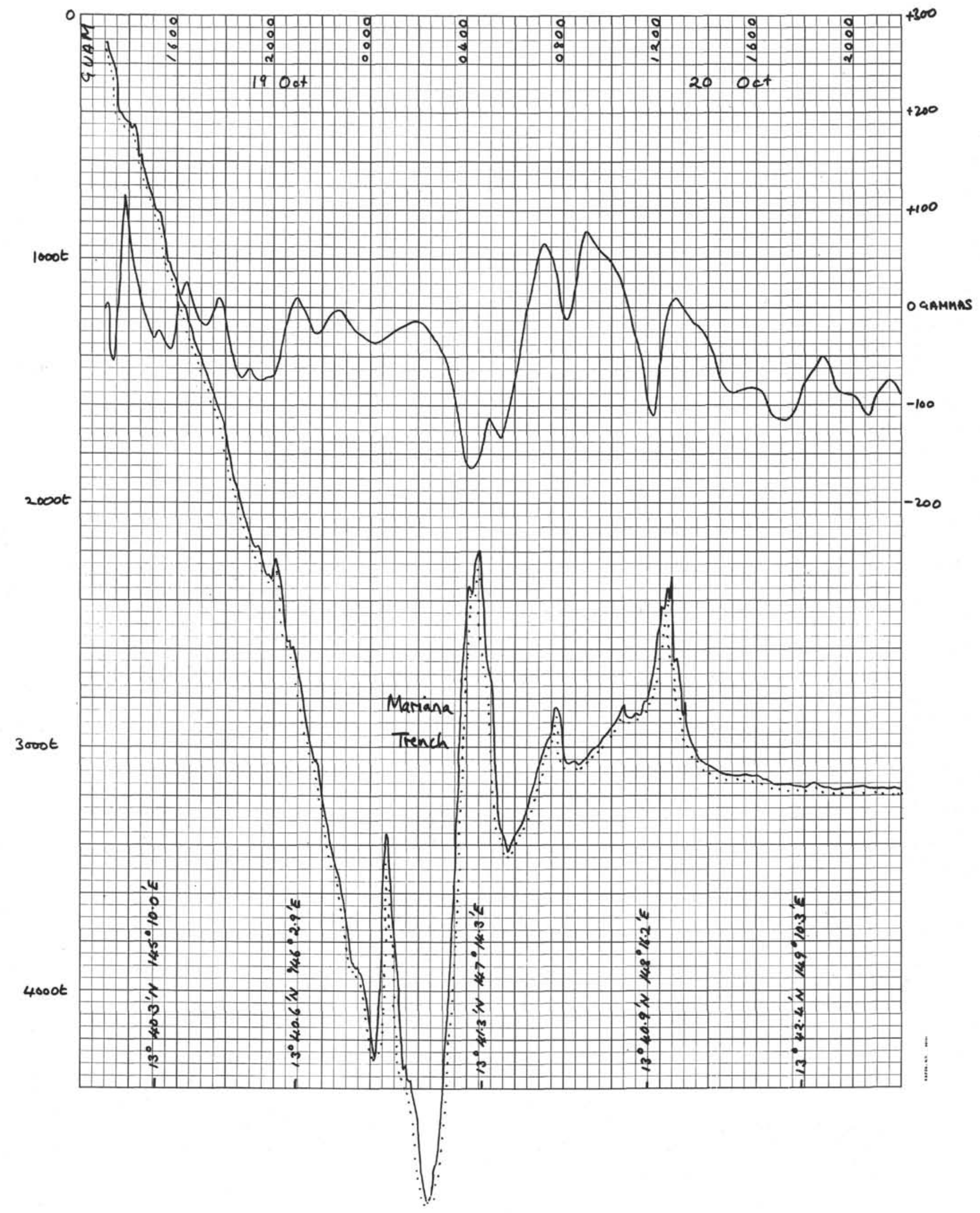




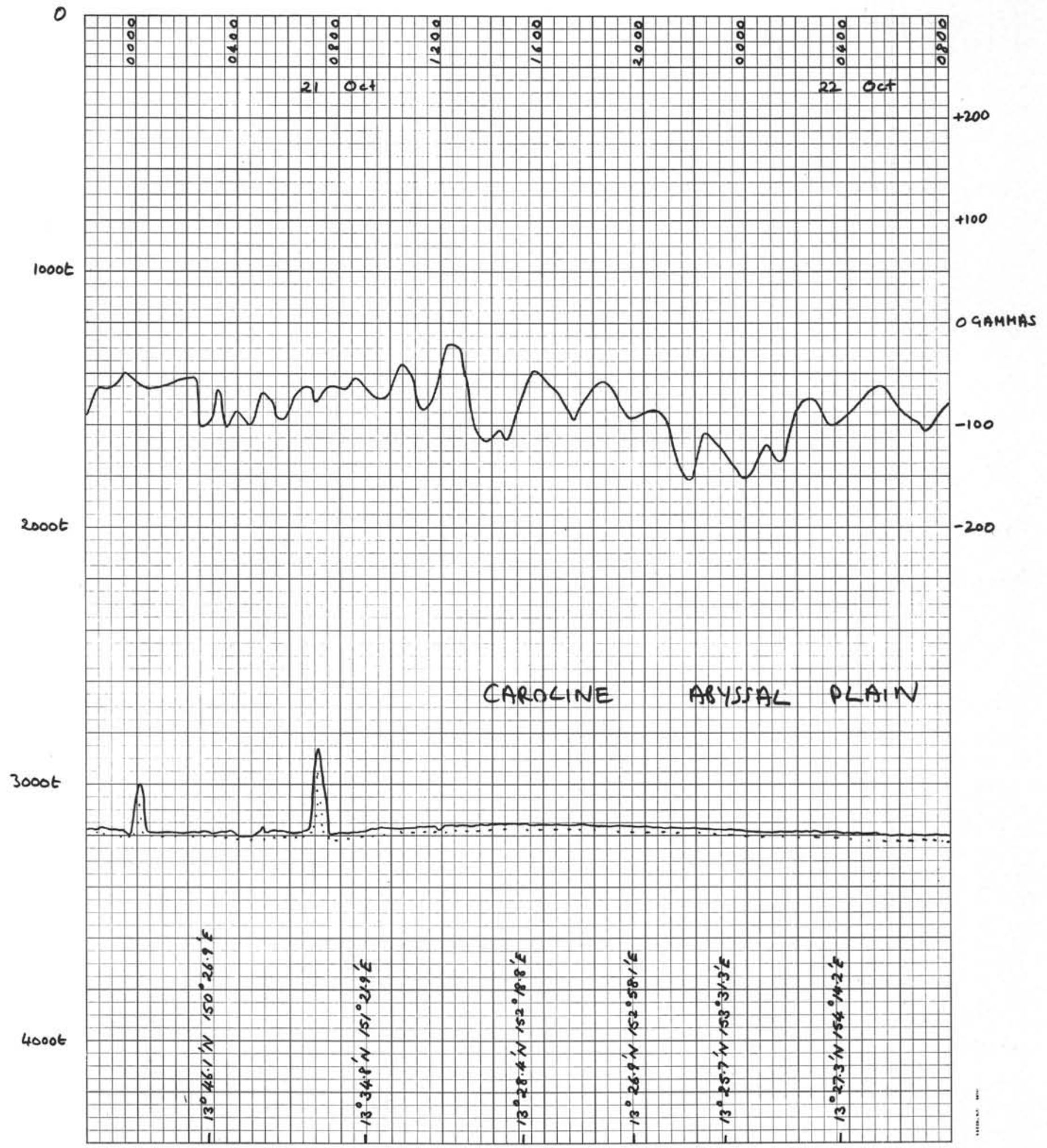




\section{E. J. W. JONES, B. C. HEEZEN}

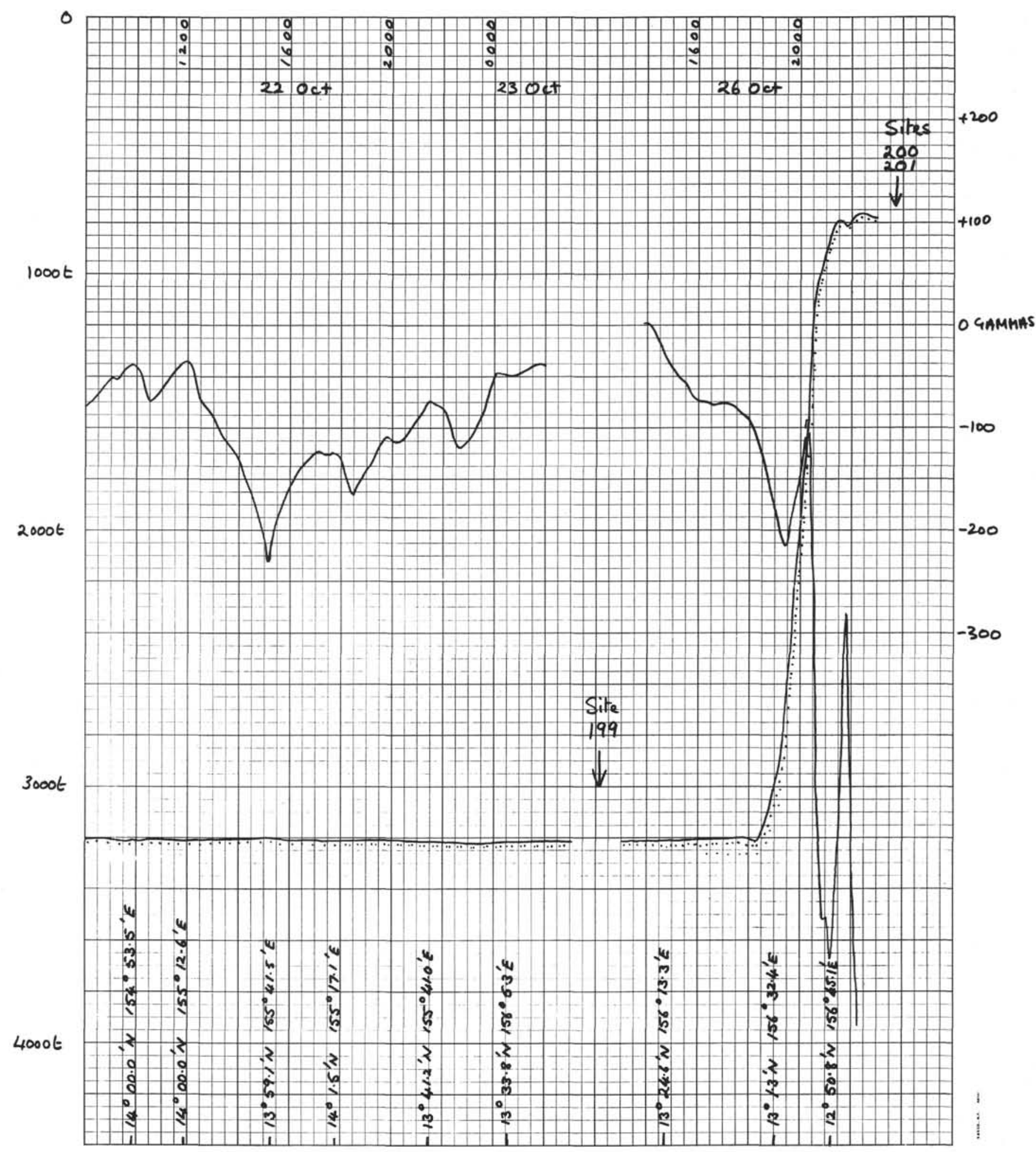




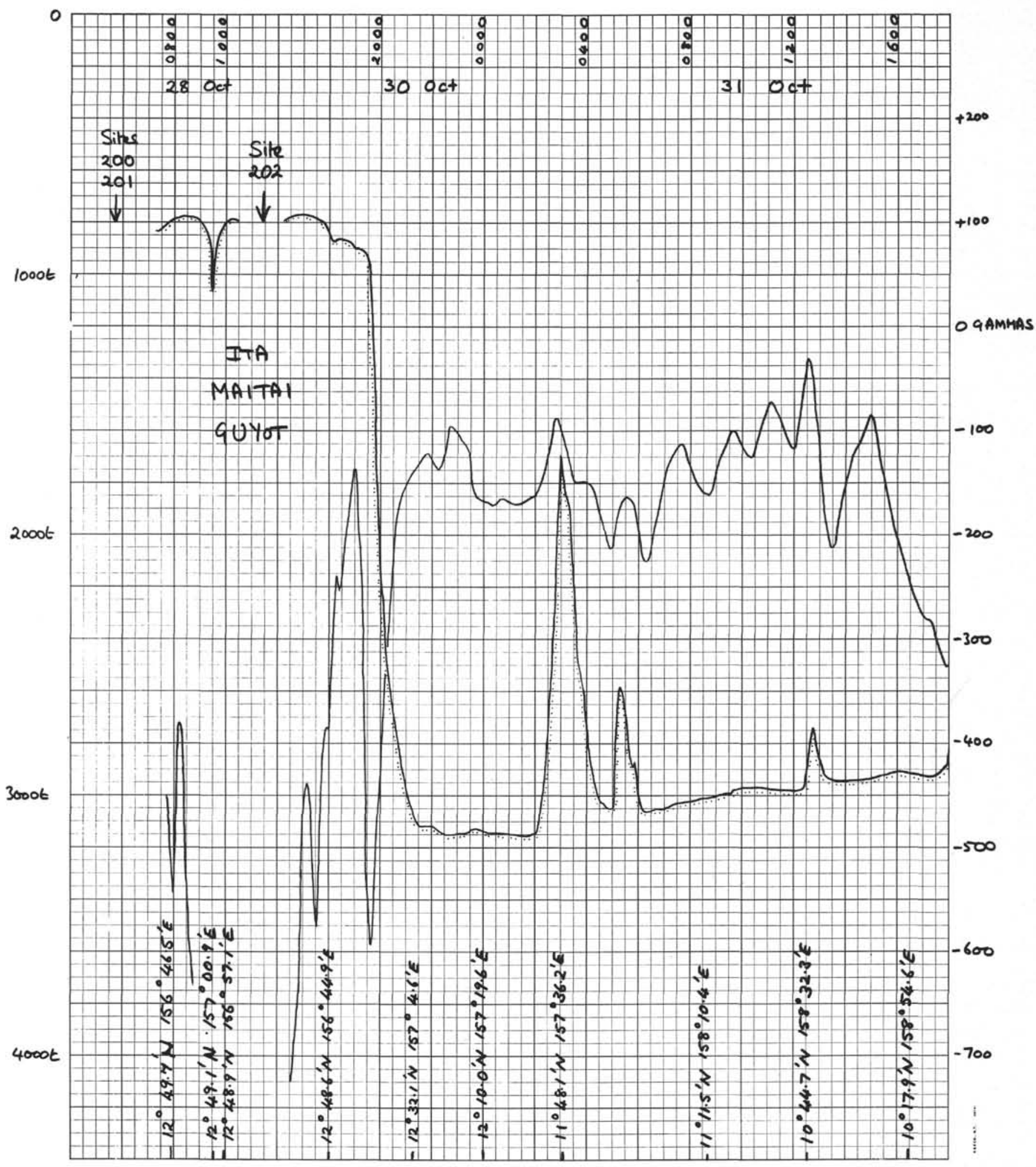


E. J. W. JONES, B. C. HEEZEN

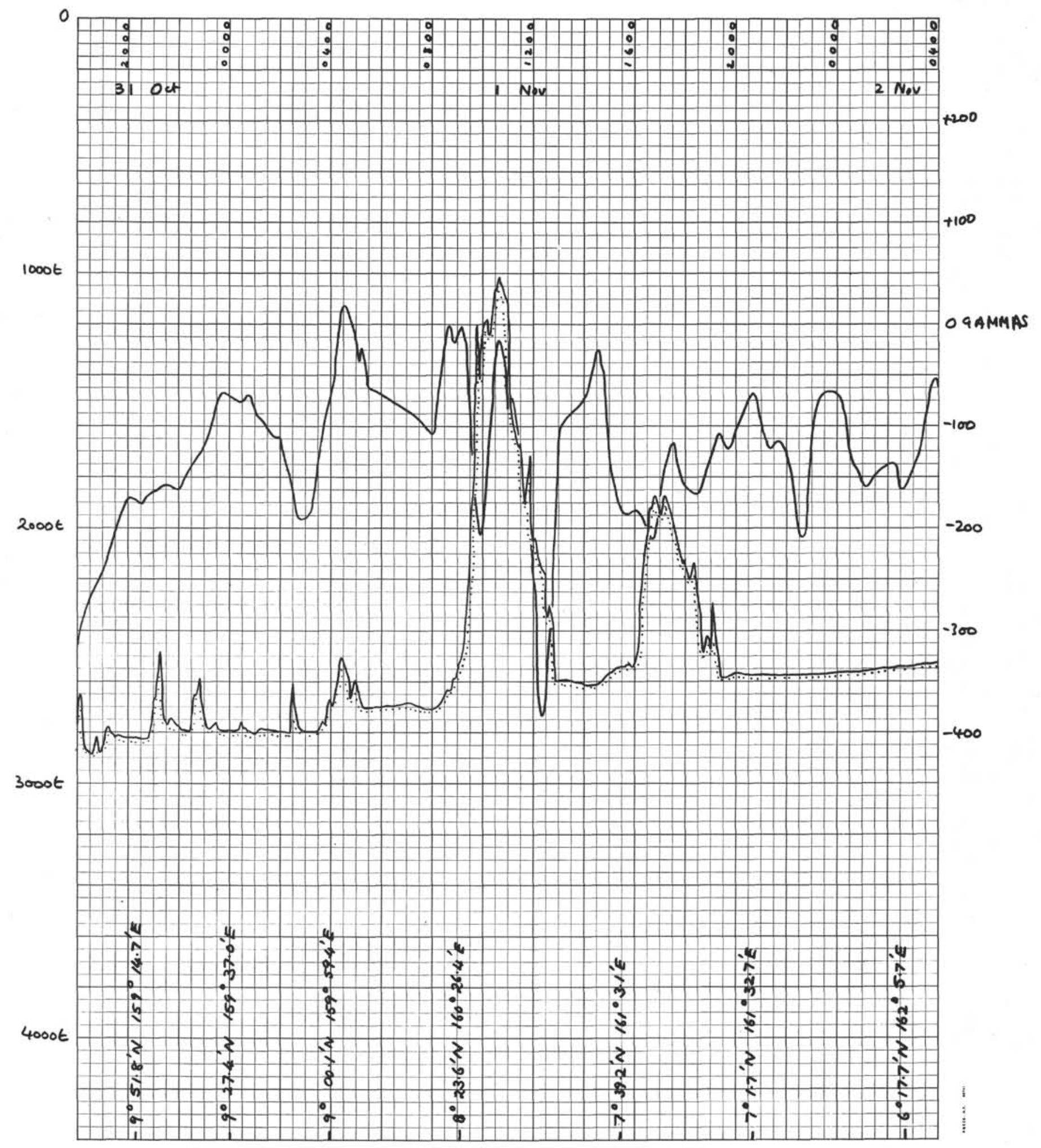




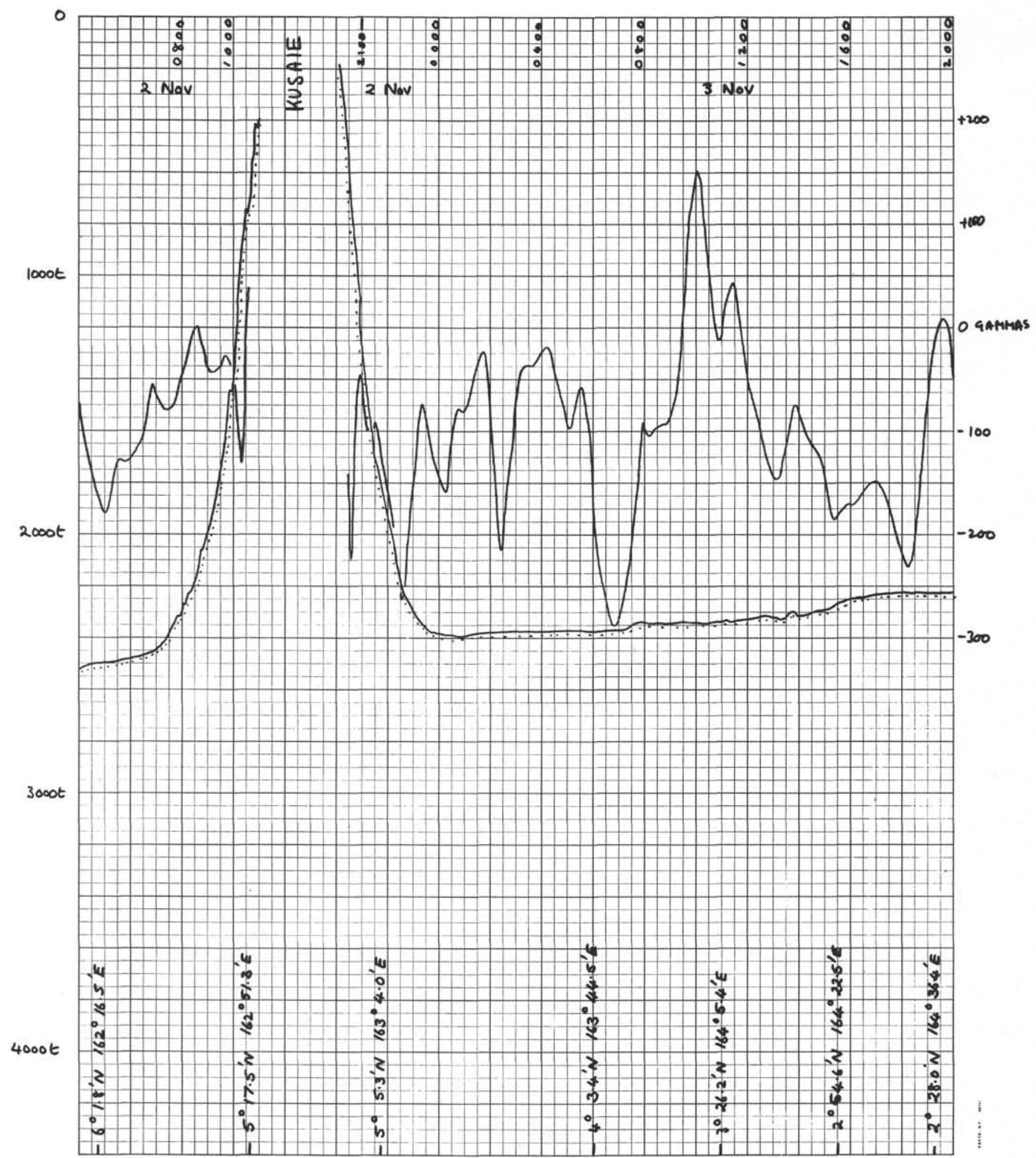


E. J. W. JONES, B. C. HEEZEN

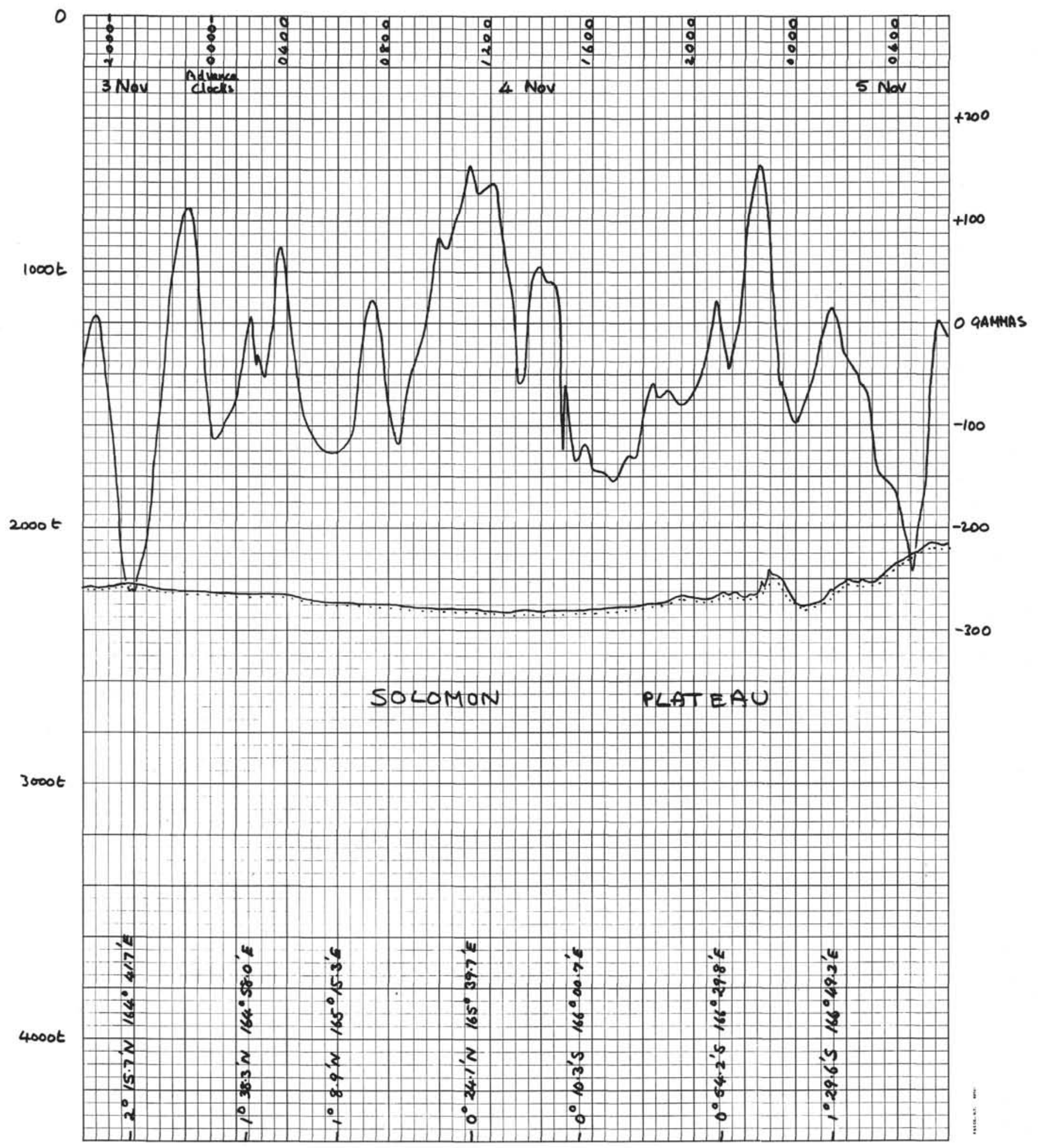




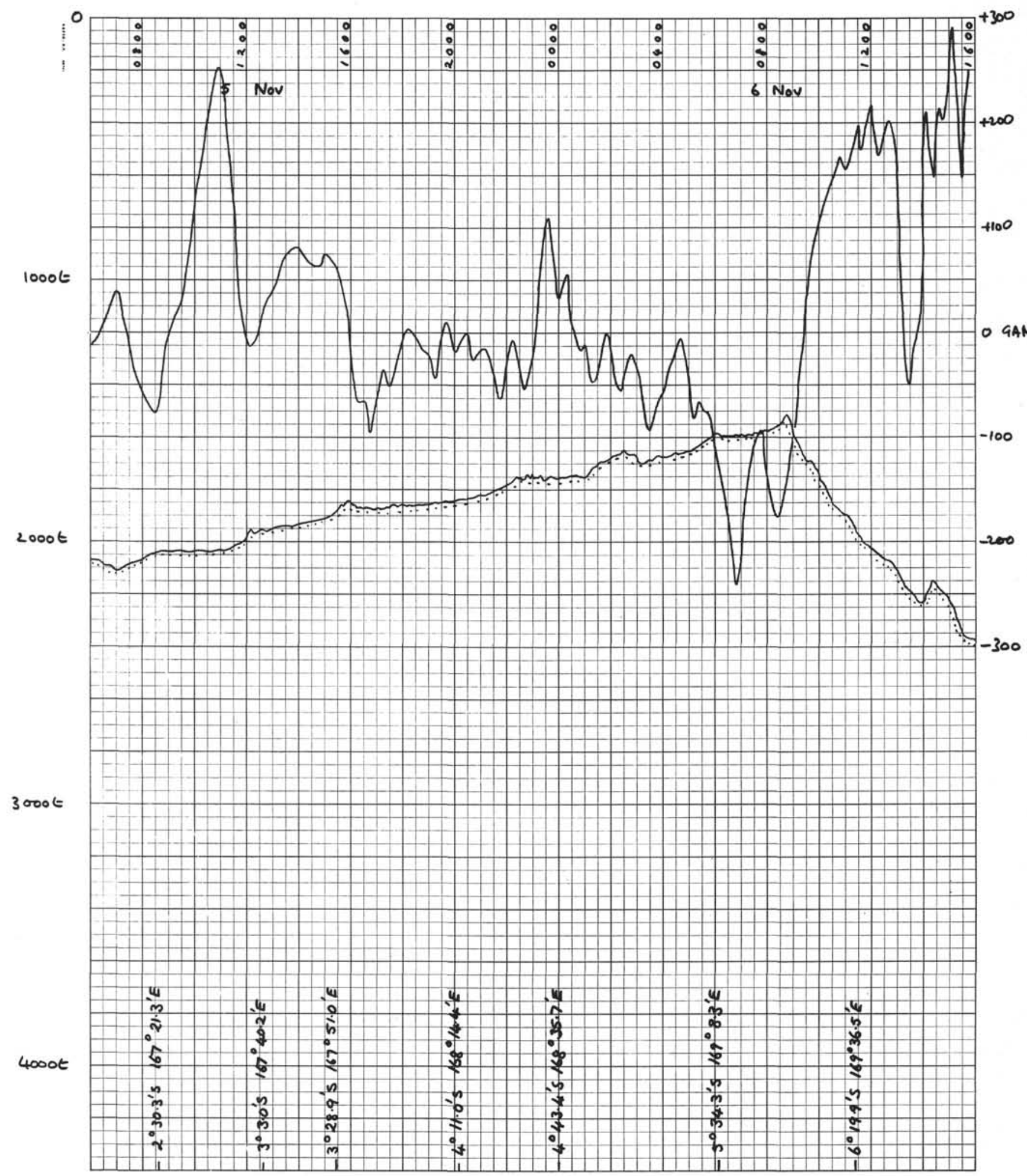


E. J. W. JONES, B. C. HEEZEN

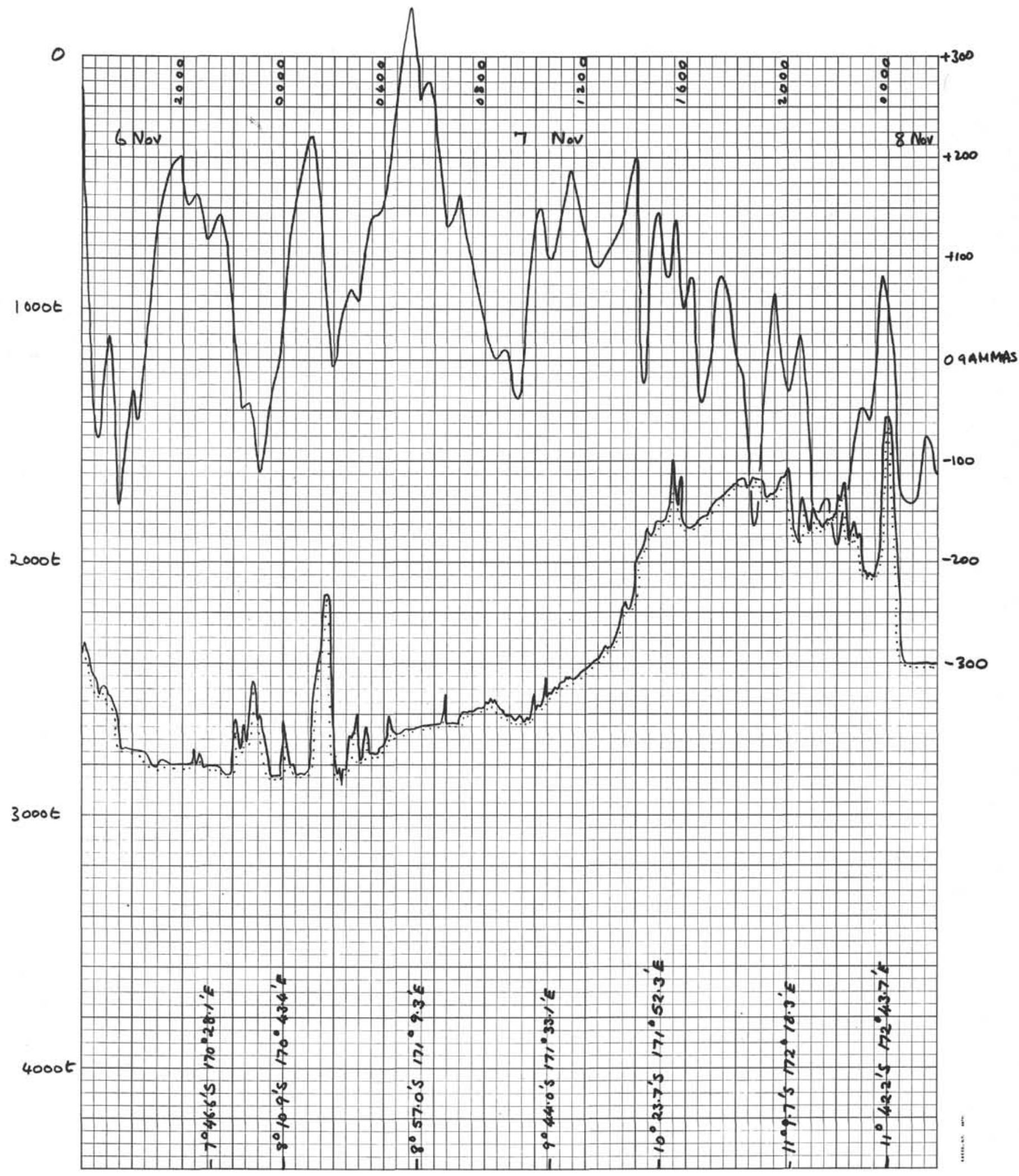




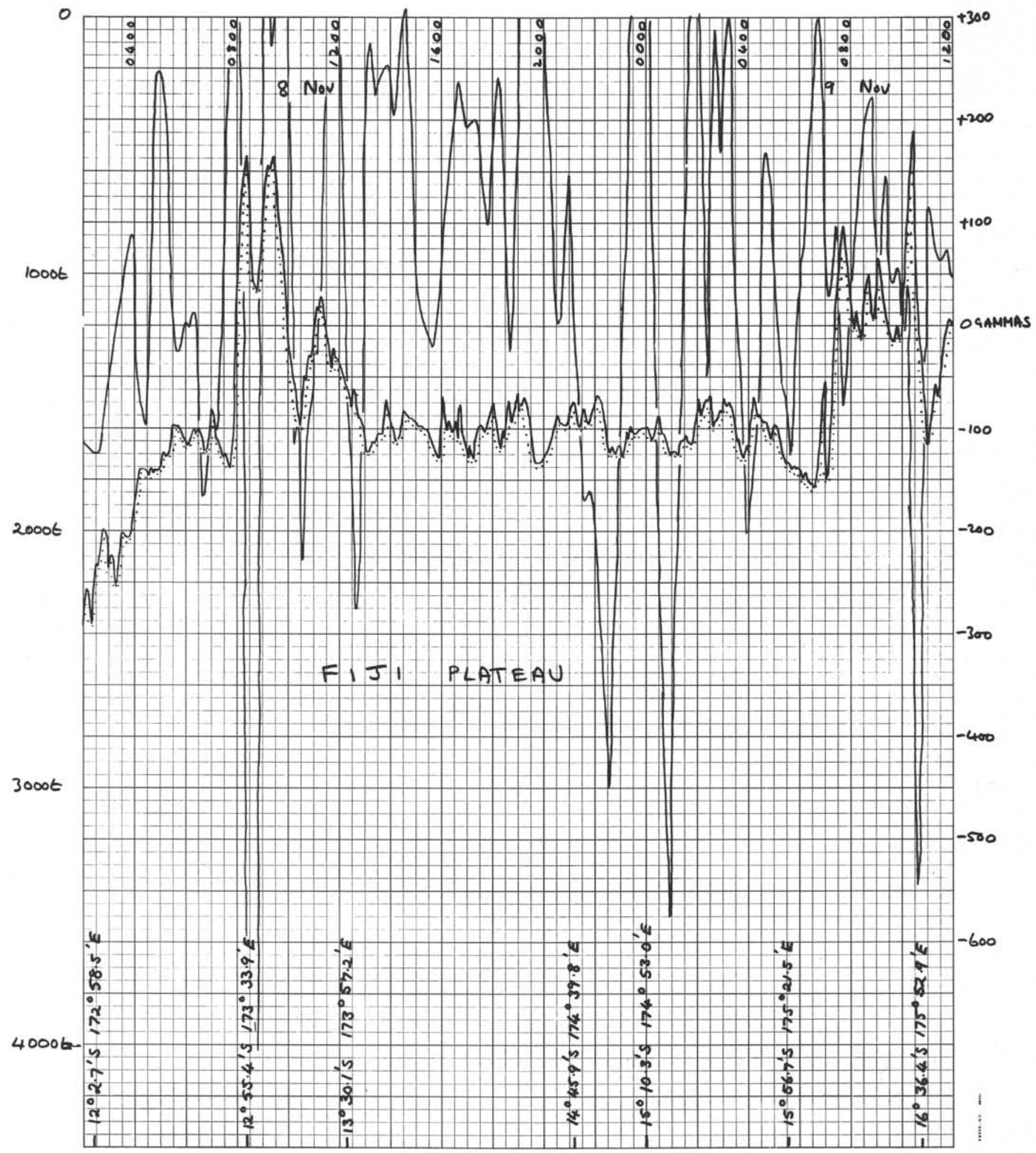


E. J. W. JONES, B. C. HEEZEN

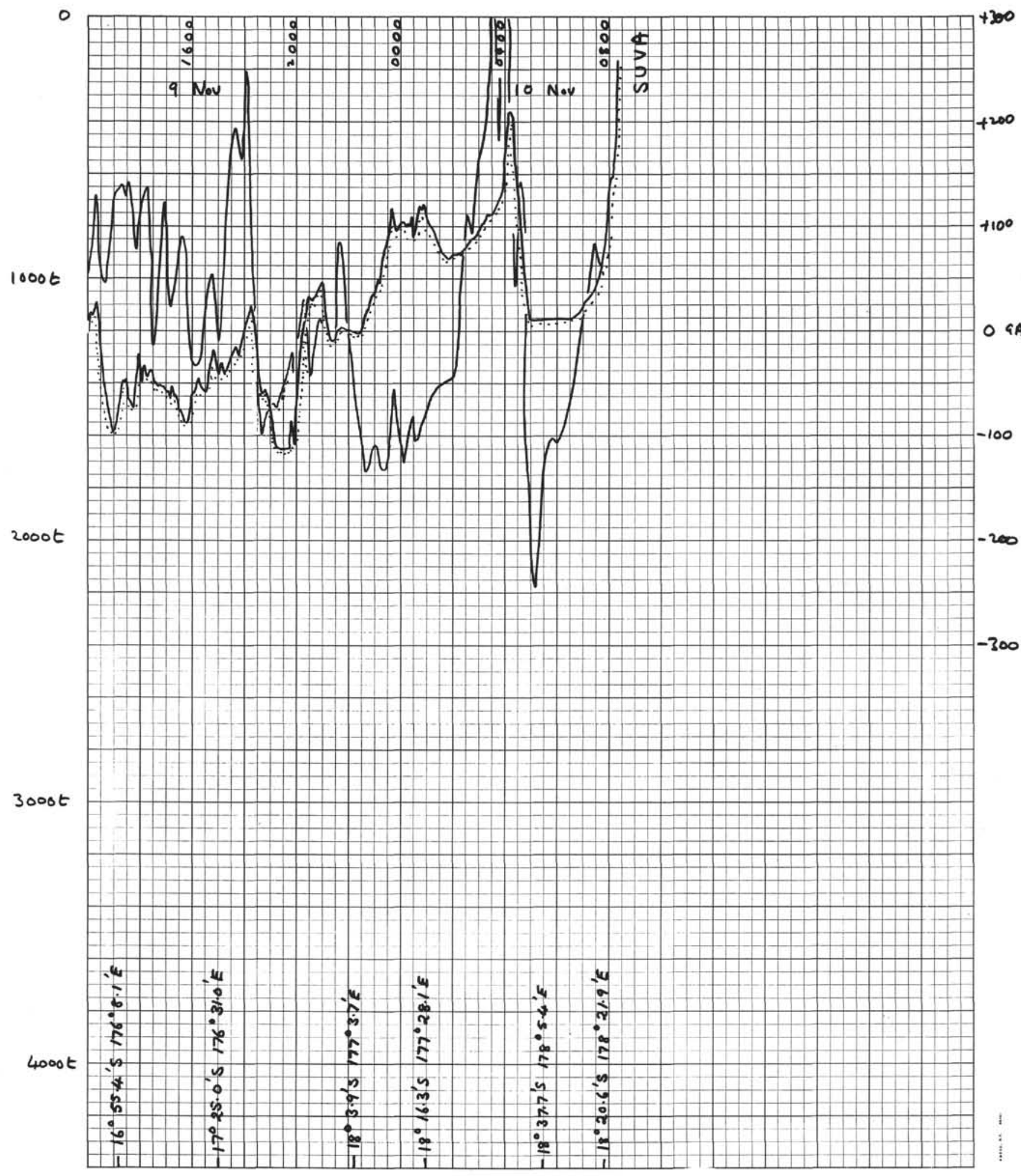

